\title{
Benefit of adjuvant chemotherapy for patients with stage IB non-small cell lung cancer: a systematic review and meta-analysis
}

\author{
Xiaofan Wang ${ }^{1 \#}$, Donglai Chen ${ }^{2 \#}$, Junmiao Wen ${ }^{3,4,5 \#}$, Yiming Mao ${ }^{6}$, Xuejuan Zhu ${ }^{1}$, Min Fan $^{3,4}$, \\ Yongbing Chen ${ }^{1}$
}

${ }^{1}$ Department of Thoracic Surgery, the Second Affiliated Hospital of Soochow University, Suzhou, China; ${ }^{2}$ Department of Thoracic Surgery, Shanghai Pulmonary Hospital, Tongji University, School of Medicine, Shanghai, China; ${ }^{3}$ Department of Radiation Oncology, Fudan University Shanghai Cancer Center, Shanghai, China; ${ }^{4}$ Department of Oncology, Shanghai Medical College, Fudan University, Shanghai, China; ${ }^{5}$ Shanghai Key Laboratory of Radiation Oncology, Shanghai, China; ${ }^{6}$ Department of Surgery, Children's Hospital of Soochow University, Suzhou, China Contributions: (I) Conception and design: D Chen, X Wang; (II) Administrative support: X Zhu, M Fan, Y Chen; (III) Provision of study materials or patients: X Wang, D Chen, J Wen, Y Mao; (IV) Collection and assembly of data: X Wang, D Chen; (V) Data analysis and interpretation: X Wang, J Wen, Y Mao; (VI) Manuscript writing: All authors; (VII) Final approval of manuscript: All authors.

"These authors contributed equally to this work.

Correspondence to: Yongbing Chen, MD, PhD. Department of Thoracic Surgery, the Second Affiliated Hospital of Soochow University, Suzhou, China. Email: chentongt@sina.com; Min Fan, MD, PhD. Department of Radiation Oncology, Fudan University Shanghai Cancer Center, Shanghai 200032, China; Department of Oncology, Shanghai Medical College, Fudan University, Shanghai 200032, China. Email: minfanfuscc@gmail.com; Xuejuan Zhu, BS. Department of Thoracic Surgery, the Second Affiliated Hospital of Soochow University, Suzhou, China. Email: zxj995062@163.com.

Background: Adjuvant chemotherapy (ACT) is routinely the recommended treatment for patients with advanced non-small cell lung cancer (NSCLC) but remains a controversial option in stage IB patients. We therefore pooled the current evidence to determine the prognostic impact of ACT in stage IB NSCLC patients in the context of the eighth tumor, node, metastasis (TNM) staging system.

Methods: Five electronic databases were searched for eligible studies up to December 2020 without language restrictions. The primary and secondary outcomes were overall survival (OS) and disease-free survival (DFS). Search results were filtered by a set of eligibility criteria and analyzed in line with PRISMA (Preferred Reporting Items for Systematic Reviews and Meta-Analyses) guidelines. The risk of bias was assessed independently using a modified set. Stata 16.0 was used for general data analysis and meta-analysis, and subgroup analyses were performed to investigate the source of interstudy heterogeneity.

Results: In all, 12 eligible studies were identified and 15,678 patients included. Our results demonstrated that ACT was associated with improved OS $[\mathrm{n}=11$; hazard ratio $(\mathrm{HR})=0.65 ; 95 \%$ confidence interval (CI): $0.60-0.70$; $\left.\mathrm{P}<0.001 ; \mathrm{I}^{2}=33.4 \%, \mathrm{P}=0.131\right]$ and DFS $\left(\mathrm{n}=9 ; \mathrm{HR}=0.73 ; 95 \% \mathrm{CI}: 0.63-0.83 ; \mathrm{P}<0.001 ; \mathrm{I}^{2}=66.7 \%, \mathrm{P}=0.002\right)$ in stage IB NSCLC patients. Subgroup analysis by histology indicated that administration of ACT conferred more favorable survival to both stage IB squamous cell carcinoma $(\mathrm{n}=1$; HR $=0.56$; 95\% CI: 0.28-0.84; $\mathrm{P}<0.001)$ and adenocarcinoma ( $\mathrm{n}=6$; HR =0.59; 95\% CI: 0.47-0.71; $\mathrm{P}<0.001 ; \mathrm{I}^{2}=31.0 \%, \mathrm{P}=0.203$ ). Meanwhile, both platinumbased ACT $\left(\mathrm{n}=7 ; \mathrm{HR}=0.62 ; 95 \%\right.$ CI: 0.51-0.74; $\left.\mathrm{P}<0.001 ; \mathrm{I}^{2}=44.8 \%, \mathrm{P}=0.093\right)$ and other regimens $(\mathrm{n}=2 ; \mathrm{HR}$ $=0.66 ; 95 \%$ CI: $0.61-0.72 ; \mathrm{P}<0.001 ; \mathrm{I}^{2}=0.7 \%, \mathrm{P}=0.316$ ) could benefit patients with stage IB disease.

Discussion: ACT might provide survival benefits to patients with stage IB NSCLC irrespective of histology or regimens. Patient selection and time trend biases were inevitable due to the limitation of retrospective studies. More prospective studies should be initiated to investigate the optimal ACT regimens in different histologic types in stage IB NSCLC patients.

Keywords: Non-small cell lung cancer (NSCLC); stage IB; adjuvant chemotherapy; meta-analysis

Submitted Jul 09, 2021. Accepted for publication Sep 09, 2021.

doi: 10.21037/atm-21-4001

View this article at: https://dx.doi.org/10.21037/atm-21-4001 


\section{Introduction}

Non-small cell lung cancer (NSCLC) has been the major cause of global lung cancer-related morbidity and mortality for decades (1). Due to the widespread adoption of thinslice computed tomography (CT) for screening pulmonary nodules, a large portion of early-stage NSCLC cases are detected, among which lung adenocarcinoma (ADC) accounts for the overwhelming majority $(2,3)$. However, the 5 -year survival of patients with early-stage NSCLCs still vary considerably, from $90 \%$ in stage IA 1 to $73 \%$ in stage IB (4). Surgical resection was previously considered to be adequate treatment for NSCLC patients without lymph node involvement (5). However, the postoperative survival of patients with stage IB disease has been unsatisfactory and marred by a high susceptibility to recurrence (6). In recent years, a number of retrospective studies (7-9) proposed that adjuvant chemotherapy (ACT) could improve the probability of freedom from recurrence and lower the death rate in both stage IB lung $\mathrm{ADC}$ and squamous cell carcinoma (SCC). However, these studies lacked up-todate and synthesized evidence concerning whether ACT should be administered to patients with stage IB NSCLC. Therefore, there is an urgent need for physicians to investigate the role of ACT in improving survival in patients with stage IB NSCLC.

The current National Comprehensive Cancer Network (NCCN) guidelines recommend postoperative chemotherapy for NSCLC patients with a tumor size $\geq 4 \mathrm{~cm}$, based on the analysis of the CALGB 9633 trial subgroup analysis (10). In the eighth tumor, node, metastasis (TNM) staging system (11), T2 was subdivided into T2a $(>3-4 \mathrm{~cm})$ and T2b ( $>4-5 \mathrm{~cm}$ ) with T2bN0M0 elevated to IIA, which had an unprecedented effect on the population eligible to receive ACT. However, it has not been specified whether patients with stage IB NSCLC $(<4 \mathrm{~cm})$ can benefit from ACT in the context of the eighth TNM staging system.

To address this issue, we conducted a systematic review meta-analysis that included a homogenous subset of stage IB NSCLC patients according to the eighth edition of the TNM classification for lung cancer, followed by a subgroup analysis comparing different chemotherapy regimens and between different pathological subtypes. We present the following article in accordance with the PRISMA reporting checklist (available at https://dx.doi.org/10.21037/atm-214001).

\section{Methods}

\section{Search Strategy}

This meta-analysis was performed in line with the PRISMA (Preferred Reporting Items for Systematic Reviews and Meta-Analyses) statement (12). We conducted searches of the PubMed, Web of Science, MEDLINE, Embase, and Cochrane Library databases to identify eligible studies published until December 2020. The main search terms were "adenocarcinoma of lung", "postoperative period", and "Drug Therapy". The full search strategy is summarized in Table S1.

\section{Study selection and inclusion criteria}

Three reviewers (Wang X., Chen D., and Wen J.) independently identified potentially eligible studies. Initially, the titles and abstracts were screened to evaluate study eligibility, which was followed by review of the full text. If any disagreement regarding study selection could not be resolved through discussion, another reviewer (Mao Y.) would be invited to reach a consensus. Studies that met the following criteria were included: (I) patients with stage IB NSCLCs according to the eighth TNM staging system and treated with cancer-directed surgery; (II) studies with hazard ratio (HR) and $95 \%$ confidence interval (CI) for overall survival (OS) or disease-free survival (DFS), or indirect information such as Kaplan-Meier curve; (III) in cases where the same population or database were included in 2 or more studies, the study with the largest sample size or the most recent information would be included. The exclusion criteria have been described in our previous study (13).

\section{Data extraction}

Data extraction was conducted by 2 reviewers (Wang $\mathrm{X}$. and Chen D.) independently. The following demographic and clinicopathological characteristics were recorded: author's name, year of publication, country or region, study design, inclusion period, number of patients, age of patients, histology, ACT regimen, follow-up period, study end points, analysis of $\mathrm{HR}$, and adjustment of variables. In addition, 2 reviewers (Wen J. and Mao Y.) also extracted individual HR estimates and corresponding 95\% CIs for OS or DFS. If some studies included stage I-III patients, only the data of patients with stage IB (tumor size $\leq 4 \mathrm{~cm}$ ) disease 
were extracted for analyses. Studies were excluded if the individual data of stage IB patients were unavailable.

\section{Definitions of study end points}

The primary end point was OS, defined as the interval between the initial surgery and death from any cause. The secondary end point was DFS, defined as the time from the initial surgery to the first recorded recurrence.

\section{Quality assessment}

In the present study, we compared surgery plus ACT with surgery alone by estimating HRs for OS and DFS. The risk of bias was assessed by 2 reviewers (Wang X. and Chen D.) independently using a modified set of predefined criteria (14) described previously (13). A score of 7 or higher was considered as a high-quality score, whereas a score of less than 7 was a low-quality one. Disagreements, if any, were resolved through discussion.

\section{Statistical analyses}

To minimize interference caused by the number of studies, differences between studies were estimated using $\mathrm{I}^{2}$ test, rather than Cochran's Q test (15), as results of Cochran's $\mathrm{Q}$ test were strongly correlated with the number of included studies. The heterogeneity was graded as low $\left(\mathrm{I}^{2}<25 \%\right)$, moderate $\left(\mathrm{I}^{2}=25-75 \%\right)$, or high $\left(\mathrm{I}^{2}>75 \%\right)$. When heterogeneity was significant $\left(\mathrm{I}^{2}>50 \%\right.$ or $\left.\mathrm{P}<0.1\right)$, a random effects model would be employed to calculate the pooled effect; otherwise, a fixed effects model would be applied.

For general data analysis and meta-analysis, Stata 16.0 (StataCorp, College Station, TX, USA) was used. Subgroup analyses were performed to investigate the source of interstudy heterogeneity. Sensitivity analyses were also carried out by omitting single a study to assess the stability of the results. A simple funnel plot-based method would be applied if publication bias was confirmed with recalculated pooled estimates (16). All statistical tests were 2 -sided, and statistical significance was defined as a $\mathrm{P}$ value less than 0.05 .

\section{Results}

\section{Selection of eligible studies}

Figure S1 displays the general flowchart for identifying eligible studies. In brief, 799 studies were available from online databases according to our search strategy, and 8 duplicate records were initially excluded from these studies. We further excluded 779 studies by screening titles and abstracts, as well as reviewing the full text. Eventually, 12 studies were confirmed as eligible for our present metaanalysis.

\section{Study characteristics}

A total of 15,678 patients were included in the present meta-analysis and had a median follow-up period of 53 months. Table 1 and Table S2 provide the baseline and main characteristics of the eligible studies. In summary, 10 of the 12 studies had a retrospective design and were published between 2016 and 2020; the other 2 studies were randomized clinical trials (RCTs) published before 2010. Lung ADC and SCC were the 2 main histologic types in these studies; 11 of the 12 studies reporting OS and 9 studies reporting DFS used multivariate analysis to adjust covariates. As shown in Table S3, all the included studies were identified as high quality.

\section{Adjuvant chemotherapy and clinical outcomes: $O S$ and DFS}

In the analysis of ACT benefit to OS, 11 studies comprising 14,702 patients were included. The data (Figure $1 A$ ) indicated that administration of ACT could bring improved OS to stage IB NSCLC patients (HR $=0.65$; 95\% CI: 0.60$0.70 ; \mathrm{P}<0.001)$ with moderate heterogeneity in the included studies $\left(\mathrm{I}^{2}=33.4 \%, \mathrm{P}=0.131\right)$. The stability of the OS subsets was assessed in a sensitivity analysis by omitting each single study, which did not affect the pooled HR (Figure 1B).

A total of 4,590 patients from 9 studies were involved in the analysis of ACT and DFS. The pooled data (Figure 1C) indicated that administration of ACT confers an advantage in freedom from recurrence to stage IB patients ( $\mathrm{HR}=0.73$; 95\% CI: $0.63-0.83 ; \mathrm{P}<0.001)$ with moderate heterogeneity $\left(\mathrm{I}^{2}=66.7 \% ; \mathrm{P}=0.002\right)$. Similar to the analysis of OS, a stable pooled HR was shown in our sensitivity analysis of the DFS subsets (Figure 1D).

We also performed subgroup analyses to investigate potential sources of heterogeneity (Tables 2,3). There were no remarkable changes in the pooled HRs for most subgroups, except for the ones by number of included individuals. Surprisingly, subgroup analysis indicated that ACT negatively affected OS $(\mathrm{n}=4$; HR $=1.115 ; 95 \% \mathrm{CI}$ : 
Table 1 Baseline characteristics of the associations between adjuvant chemotherapy and clinical outcomes in stage IB NSCLCs $(\mathrm{n}=12)$.

\begin{tabular}{|c|c|c|c|c|c|c|c|c|c|c|c|c|}
\hline No. & Study & $\begin{array}{l}\text { Country or region (inclusion } \\
\text { period) }\end{array}$ & Study design & $\begin{array}{l}\text { Gender (female/ } \\
\text { male) (\%) }\end{array}$ & $\begin{array}{l}\text { Median age } \\
\text { (years) }\end{array}$ & Tumor type & Histology & $\begin{array}{l}\text { Median follow-up } \\
\text { period (months) }\end{array}$ & Study end points & Chemotherapy regimens & $\begin{array}{l}\text { Surgical alone/surgery plus } \\
\text { ACT }\end{array}$ & $\begin{array}{l}\text { Quality } \\
\text { score }\end{array}$ \\
\hline 1 & $\begin{array}{l}\text { Morgensztern } \\
\text { [2016] }\end{array}$ & United States [2004-2011] & Retrospective & $44.2 / 55.8$ & NR & NSCLC & $43.6 \%$ SCC; $43.9 \%$ ADC; $12.5 \%$ other & 60 & os & NR & $\begin{array}{c}1,608 / 8,979 \\
(15.19 \% / 84.81 \%)\end{array}$ & 7 \\
\hline 2 & Xu [2018] & China [2008-2014] & Retrospective & $5.6 / 94.4$ & NR & Lung SCC & - & 45.9 & OS/DFS & $\begin{array}{c}4 \text { cycles of platinum-based or single- } \\
\text { agent chemotherapy }\end{array}$ & 201/159 (55.83\%/44.17\%) & 8 \\
\hline 3 & Strauss [2008] & United States [1996-2003] & $\mathrm{RCT}$ & $36.0 / 64.0$ & 61 & NSCLC & $34.3 \%$ SCC; $51.5 \%$ ADC; $14.2 \%$ other & 74 & OS/DFS & $\begin{array}{c}4 \text { cycles of paclitaxel } 200 \mathrm{mg} / \mathrm{mL}+ \\
\text { carboplatin } 6 \mathrm{mg} / \mathrm{mL}\end{array}$ & $63 / 71(47.01 \% / 52.99 \%)$ & 8 \\
\hline 4 & Qian [2017] & China [2008-2015] & Retrospective & $61.6 / 38.4$ & 60 & Lung ADC & $\begin{array}{c}66.2 \% \text { SMPN; } 23.8 \% \text { SMPM; } 10.0 \% \\
\text { SMPP }\end{array}$ & 46.8 & DFS & $\begin{array}{l}4 \text { cycles of platinum-based } \\
\text { chemotherapy }\end{array}$ & $488 / 488(50.00 \% / 50.00 \%)$ & 7 \\
\hline 5 & Butts [2010] & United States [2004-2011] & $\mathrm{RCT}$ & $34.0 / 65.1$ & 60.9 & NSCLC & $37.1 \%$ SCC; $53.1 \%$ ADC; $9.8 \%$ other & 111.6 & os & $\begin{array}{c}4 \text { cycles of vinorelbine/cisplatin or } \\
\text { observation }\end{array}$ & $45 / 54(45.45 \% / 54.55 \%)$ & 8 \\
\hline 6 & Wang [2018] & China [2003-2014] & Retrospective & $35.9 / 64.1$ & 60 & NSCLC & $33.0 \%$ SCC; $60.0 \%$ ADC; $7.0 \%$ other & 56.04 & os & $\begin{array}{l}4-6 \text { cycles of cisplatin with } \\
\text { gemcitabine or paclitaxel }\end{array}$ & 265/137 (65.92\%/34.08\%) & 7 \\
\hline 7 & Wang [2019] & China [2007-2013] & Retrospective & $54.7 / 45.3$ & 59 & Lung ADC & $\begin{array}{c}\text { 1.9\% LEP; } 53.3 \% \text { ACN; } 32.1 \% \text { PAP; } \\
\text { 9.4\% SOL; } 1.4 \% \text { MIP; } 1.9 \% \text { other }\end{array}$ & 46.7 & OS/DFS & platinum-based & 106/106 (50.00\%/50.00\%) & 8 \\
\hline 8 & Chen [2020] & China [2009-2016] & Retrospective & 44.6/55.4 & 65 & Lung ADC & $\begin{array}{c}27.9 \% \text { LEP; } 30.0 \% \text { ACN; } 17.9 \% \text { PAP; } \\
\text { 16.6\% SOL; } 7.7 \% \text { MIP }\end{array}$ & 90.8 & OS/DFS & platinum-based & $468 / 859(35.27 \% / 64.73 \%)$ & 8 \\
\hline 9 & Jang [2017] & Korea [2000-2009] & Retrospective & $50.9 / 49.1$ & 63.1 & Lung ADC & - & 49.3 & OS/DFS & platinum-based & $110 / 218(33.54 \% / 66.46 \%)$ & 7 \\
\hline 10 & Ito [2020] & Japan [2008-2015] & Retrospective & $46.1 / 53.9$ & 64.9 & Lung ADC & $\begin{array}{l}\text { 35.2\% LEP; } 24.2 \% \text { ACN; } 18.4 \% \text { PAP; } \\
\text { 15.4\% SOL; 1.0\% MIP; } 5.8 \% \text { other }\end{array}$ & 66.0 & OS/DFS & UFT for at least 6 months & $70 / 70(50.00 \% / 50.00 \%)$ & 8 \\
\hline 11 & Cao [2018] & China [2006-2015] & Retrospective & $35.6 / 64.4$ & 60 & Lung ADC & NR & 41 & OS/DFS & platinum-based & 193/116 (62.46\%/37.54\%) & 8 \\
\hline 12 & Chen [2018] & China [2010-2015] & Retrospective & $58.6 / 41.4$ & NR & Lung $A D C$ & NR & 34.27 & OS/DFS & $\begin{array}{l}4 \text { cycles of platinum-based } \\
\text { chemotherapy }\end{array}$ & $402 / 402(50.00 \% / 50.00 \%)$ & 8 \\
\hline
\end{tabular}

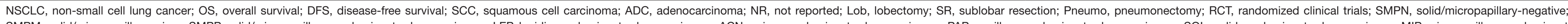

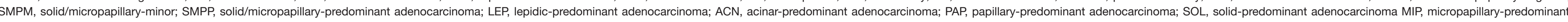
adenocacinof 

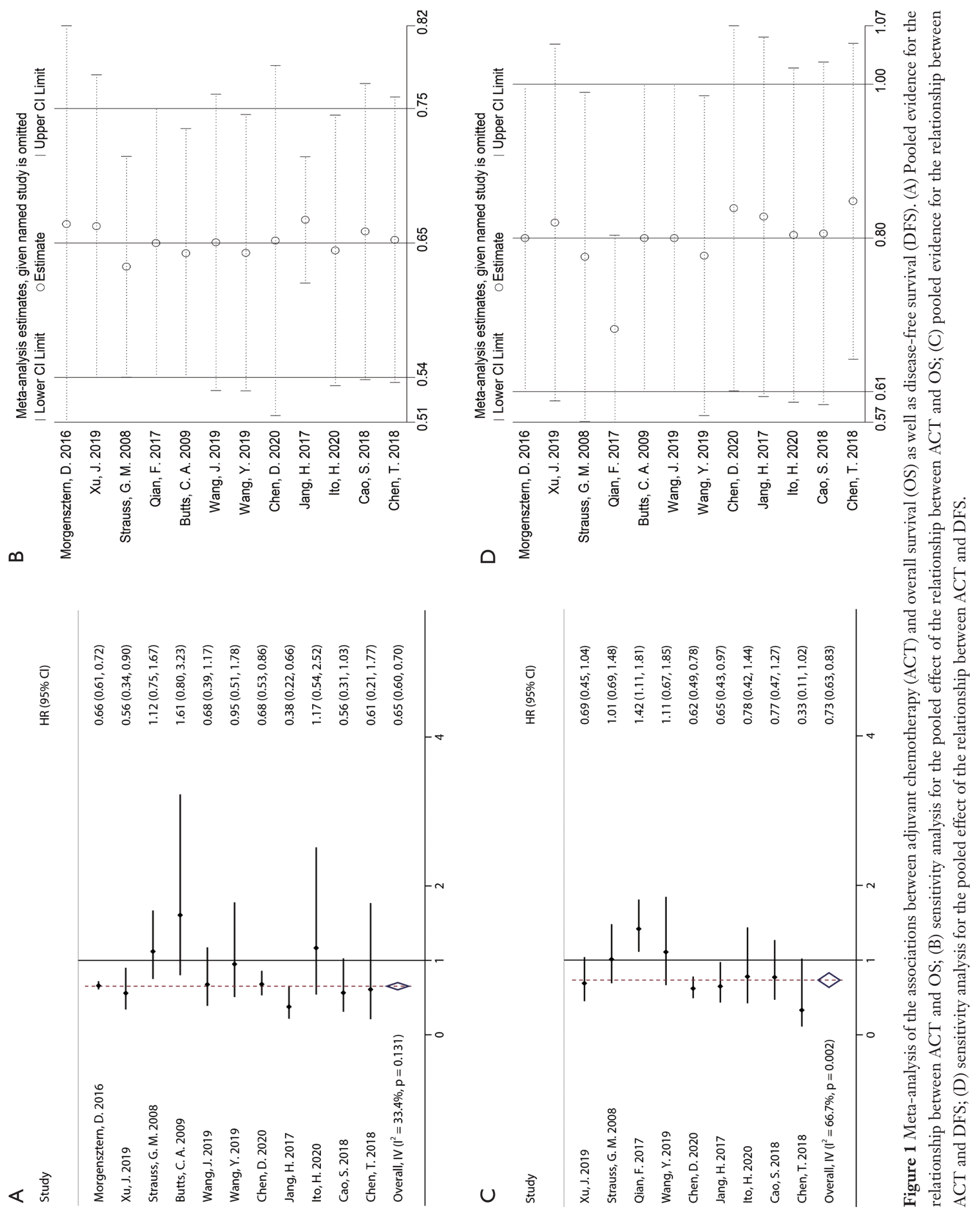
Table 2 Subgroup analyses of the associations between adjuvant chemotherapy and OS

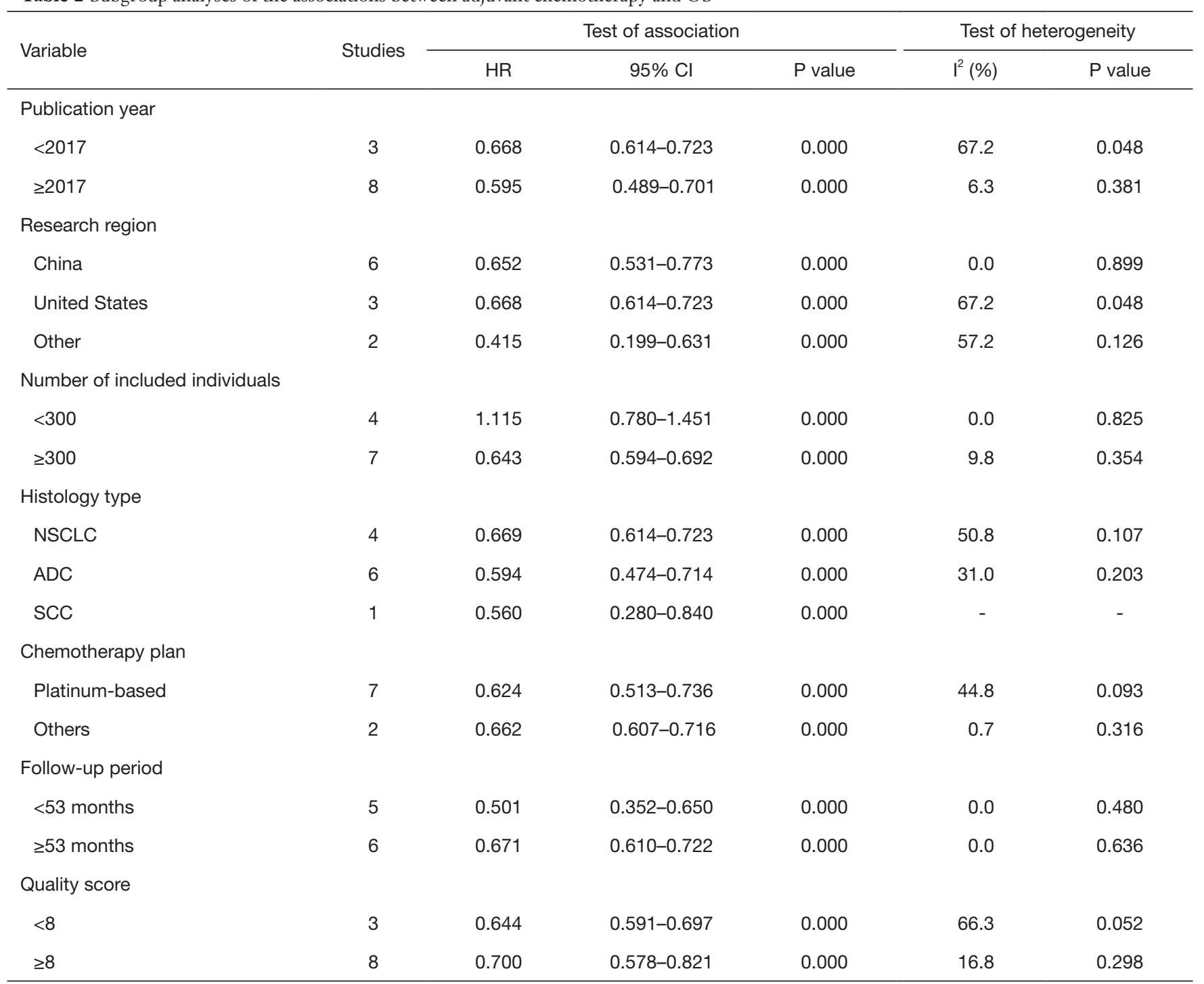

OS, overall survival; HR, hazard ratio; 95\% Cl, 95\% confidence interval; NSCLC, non-small cell lung cancer; ADC, adenocarcinoma; SCC, squamous cell carcinoma.

0.780-1.451; $\mathrm{P}<0.001)$ but benefited DFS $(\mathrm{n}=3 ; \mathrm{HR}=0.963$; 95\% CI: 0.688-1.239; $\mathrm{P}<0.001)$ in small-scale studies with extremely low heterogeneity (OS: $\mathrm{I}^{2}=0.0 \%, \mathrm{P}=0.825$; DFS: $\mathrm{I}^{2}=0.0 \%, \mathrm{P}=0.673$; Tables 2,3$)$. Interestingly, subgroup analysis by different follow-up periods revealed that administration of ACT stably improved OS irrespective of the length of follow-up (Figure S2).

\section{Adjuvant chemotherapy and OS: histology and regimens}

As shown in Figure 2A, a pooled analysis of 1 study (9) demonstrated the role of ACT in stage IB lung SCC. By pooling the available evidence, we found that ACT administration was associated with significantly better OS in stage IB SCC (HR $=0.56$; 95\% CI: 0.28-0.84; $\mathrm{P}<0.001$ ). Meanwhile, a pooled analysis of 6 studies (17-22) compared the OS of stage IB lung ADC patients treated with surgery plus ACT with that of patients treated with surgery alone. Similarly, the pooled HR showed that ACT was associated with improved OS in stage IB ADC (HR $=0.59$; $95 \%$ CI: $0.47-0.71 ; \mathrm{P}<0.001)$, and a moderate statistical heterogeneity was suggested regarding this result $\left(\mathrm{I}^{2}=31.0 \%\right.$, 
Table 3 Subgroup analyses of the associations between adjuvant chemotherapy and DFS

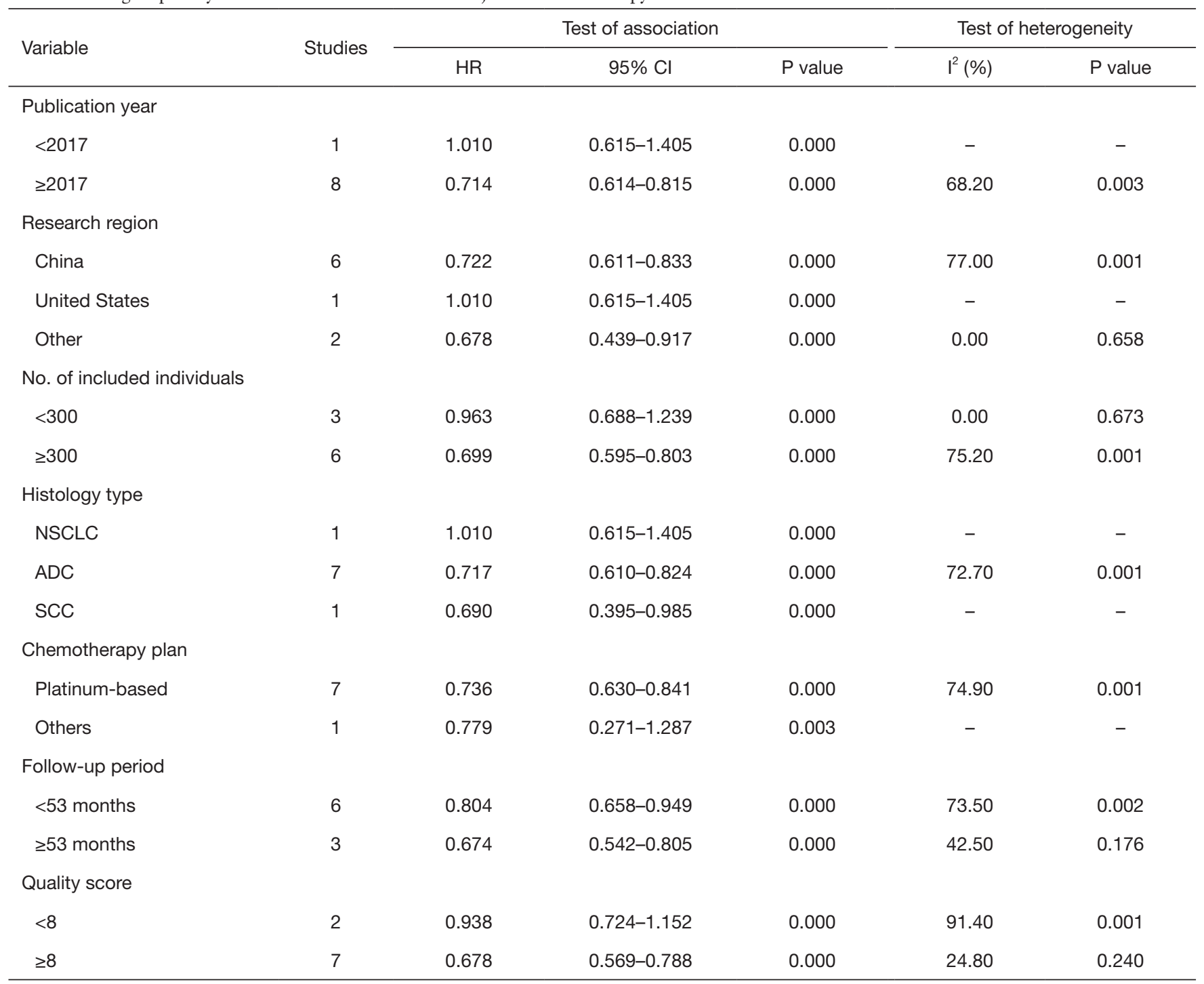

DFS, disease-free survival; HR, hazard ratio; $95 \% \mathrm{Cl}$, $95 \%$ confidence interval; NSCLC, non-small cell lung cancer; ADC, adenocarcinoma; SCC, squamous cell carcinoma.

$\mathrm{P}=0.203)$.

We also performed a pooled analysis of 7 studies $(10,17-19,21-23)$ to assess the impact of platinum-based regimens in stage IB NSCLC patients receiving ACT (Figure 2B). The pooled analysis indicated that platinumbased ACT was associated with favorable OS in stage IB patients $(\mathrm{HR}=0.62 ; 95 \% \mathrm{CI}: 0.51-0.74 ; \mathrm{P}<0.001)$ with moderate heterogeneity $\left(\mathrm{I}^{2}=44.8 \%, \mathrm{P}=0.093\right)$. Meanwhile, a pooled analysis of 2 studies $(20,24)$ investigated other regimens in stage IB NSCLC patients receiving ACT (Figure 2B). The pooled data revealed that administration of other regimens could also be beneficial to stage IB patients (HR $=0.66 ; 95 \%$ CI: 0.61-0.72; $\mathrm{P}<0.001)$. Additionally, there was evidence of extremely low heterogeneity for this result $\left(\mathrm{I}^{2}=0.7 \%, \mathrm{P}=0.316\right)$.

\section{Publication bias}

As shown in Table S4, Begg's and Egger's tests confirmed that there was no significant publication bias in terms of HRs for OS (Begg's test, $\mathrm{P}=0.436$; Egger's test, $\mathrm{P}=0.379$ ) or DFS (Begg's test, $\mathrm{P}=1.000$; Egger's test, $\mathrm{P}=0.481$ ). 
A subgroup and study

$\mathrm{HR}(95 \% \mathrm{Cl})$

$$
\text { SCC }
$$

Xu, J. 2019

Subgroup, IV $\left(I^{2}=0.0 \%, p=.\right)$

ADC

Wang, Y. 2019

Chen, D. 2020

Jang, H. 2017

Ito, H. 2020

Cao, S. 2018

Chen, T. 2018

Subgroup, IV $\left(I^{2}=31.0 \%, p=0.203\right)$

Heterogeneity between groups: $p=0.827$

Overall, IV $\left(I^{2}=17.8 \%, p=0.294\right)$

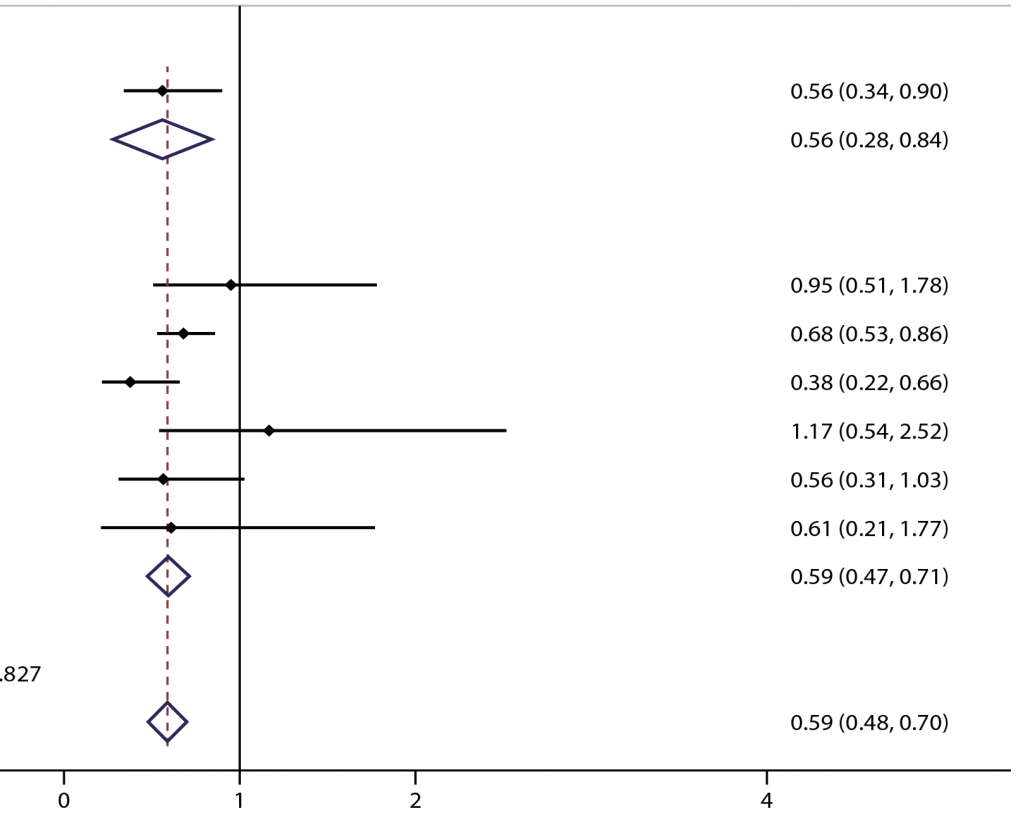

B subgroup and study

$\operatorname{HR}(95 \% \mathrm{Cl})$

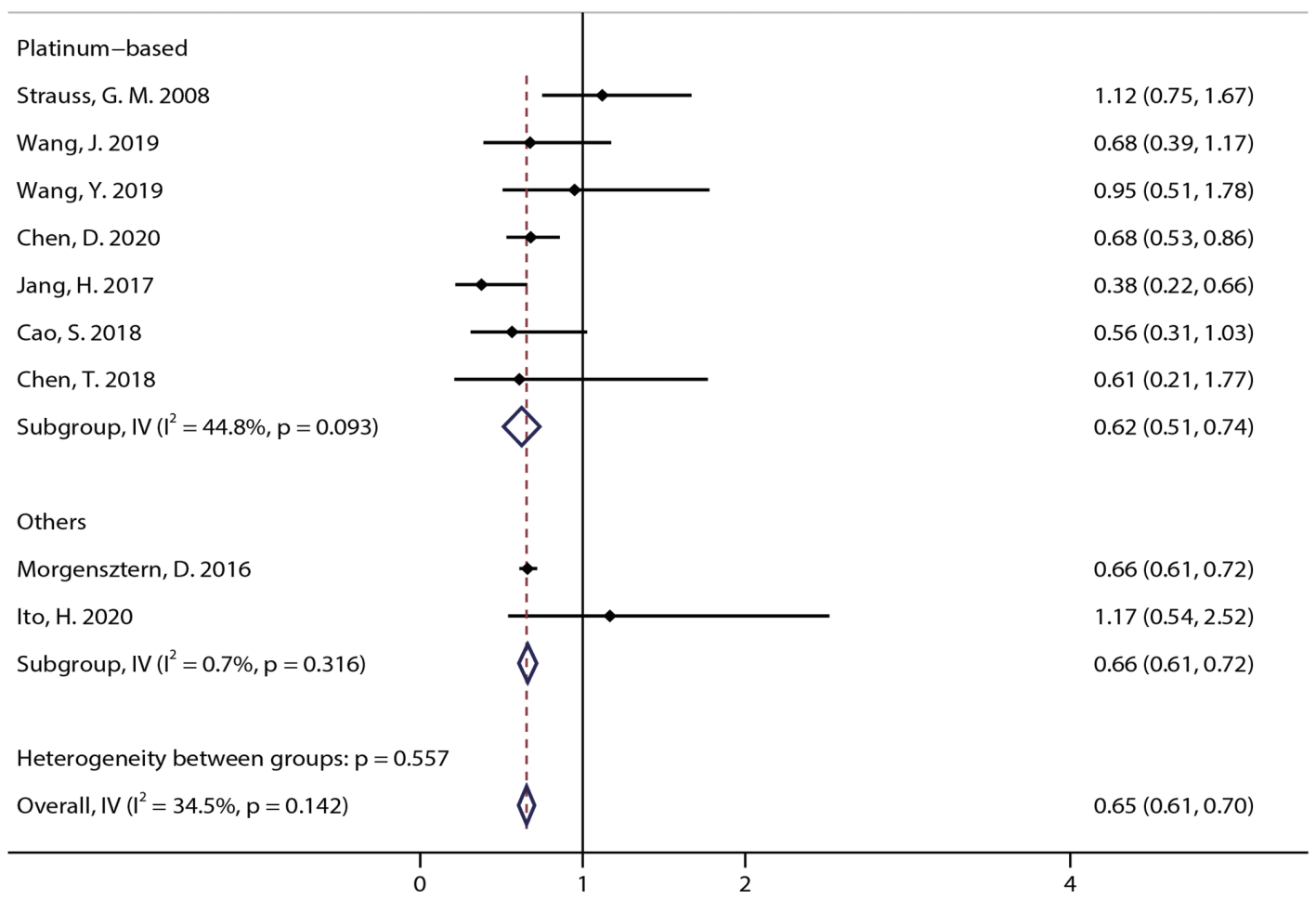

Figure 2 Subgroup analyses of (A) the associations between lung adenocarcinoma (ADC) and squamous cell carcinoma (SCC) and (B) the associations between platinum-based chemotherapy and other chemotherapy. 


\section{Discussion}

This systematic review and meta-analysis show that administration of ACT might bring benefits in OS and DFS to stage IB patients within the context of the eighth edition of TNM staging system. Furthermore, ACT exhibited its value not only in patients with SCC but also in those with ADC. Moreover, subset analyses indicated that both platinum-based regimens and others could effectively prolong the OS of stage IB patients. Interestingly, subset analysis by follow-up period also suggested that administration of ACT could improve both short- and long-term OS. To the best of our knowledge, this study is the largest and most recent meta-analysis of its kind to demonstrate the prognostic impact of ACT on stage IB NSCLCs since the widespread application of the eighth edition TNM classification.

In this study, we identified 12 relevant studies to determine the prognostic impact of ACT on stage IB NSCLC patients. Notably, 7 of the 12 eligible studies (9,18,19,21-24) showed the prescription of ACT to be associated with better OS in patients with stage IB NSCLC. However, the other 5 studies $(8,10,17,20,25)$ did not support routine use of ACT for patients with stage IB NSCLC. Consequently, the pooled evidence not only highlighted a clear survival benefit of ACT in both the OS $(\mathrm{n}=11 ; \mathrm{HR}=0.65 ; 95 \%$ CI: $0.60-0.70 ; \mathrm{P}<0.001)$ and DFS $(\mathrm{n}=9 ; \mathrm{HR}=0.73 ; 95 \%$ CI: $0.63-0.83 ; \mathrm{P}<0.001)$ of stage IB patients, but also addressed the debate of whether ACT should be administered even for malignancies $<4 \mathrm{~cm}$. The recent increase in early-stage ADC presenting as pulmonary nodules detected by CT examination has led to a surge in surgical patients, and prescribing ACT for postoperative patients with pathologically identified stage IB ADC has also becomes a matter of debate. Among the 6 included studies investigating ACT and DFS in ADC patients, only $3(18,19,22)$ reported a positive influence of ACT on stage IB ADC patients. Meanwhile, only 2 studies $(18,19)$ identified survival benefits from ACT for OS in stage IB ADC patients. Interestingly, our pooled data confirmed the value of ACT for stage IB ADC (OS: $n=6$; HR $=0.594 ; 95 \%$ CI: 0.475-0.741; $\mathrm{P}<0.001$; DFS: $\mathrm{n}=7$; HR $=0.717$; $95 \%$ CI: $0.610-0.824 ; \mathrm{P}<0.001)$. In other words, the current study provides robust evidence for the administration of ACT in stage IB ADC patients, especially in those with high-grade tumor components.

Notably, the majority of included participants in the CALGB 9633 study were diagnosed with lung ADC (10).
Previous evidence suggests that patients with early-stage lung SCC might be more susceptible to recurrence of malignancies compared to those with lung ADC (26-28). In addition, there is a close link between lung SCC and smoking, one of the independent predictors of recurrence. In another study (29), stage I lung SCC patients exhibited higher expression levels of Ki67 and Bcl-2 proteins, which are associated with proliferation and metastasis, compared with ADC patients. These results suggest that timely clinical interventions should be implemented to prevent recurrence in early-stage SCC patients. Our subset analysis also indicated that patients with stage IB SCC might benefit from administration of ACT (HR $=0.56$; 95\% CI: 0.28-0.84; $\mathrm{P}<0.001)$. Therefore, more attention should be paid to prescribing prompt ACT for stage IB SCC patients.

In terms of biomarkers for predicting efficacy of ACT, Buhl et al. (30) found that molecular profiles derived from NSCLC tissues were prognostic and predictive for selection of patients benefiting from platinum-based ACT. Additionally, Lin et al. (31) showed that TP53 mutation was significantly correlated with tumor progression, which may provide a rationale for the selective use of ACT in stage IB patients with TP53 mutations. However, Ma et al. (32) claimed the opposite, as they declared that TP53 mutations were not significant predictors of outcome in ACT, but may be associated with a tendency towards worse outcomes upon treatment. In addition to tissue-based genetic testing, Kuang et al. (33) proposed that circulating tumor DNA analyses based on peripheral blood samples might define a subgroup that remained at high risk of relapse despite standard ACT, and could help to inform intensified therapeutic strategies, which was supported by other researchers (34).

Recently, several studies $(35,36)$ recommended that postoperative PD-L1 testing be performed in surgical patients and with those TPS $\geq 1 \%$ could be tried with adjuvant immunotherapy or adjuvant chemotherapy combined with or without concomitant immunotherapy. However, the robust evidence supporting administration of immune checkpoint inhibitors combined with chemotherapy as adjuvant treatment in stage IB disease has not been available in clinical practices, which awaits further investigation.

Several limitations of this study should be acknowledged. As this meta-analysis was performed mainly on retrospective studies, patient selection and time trend biases were inevitable. Second, given the limited available information, it was impossible to perform subset analyses by radiological 
features and histologic subtypes of ADCs. Notably, ADCs presenting as pure ground-glass opacity or harboring a lepidic-predominant pattern might not benefit from ACT. Third, there was inherent heterogeneity in the administration of ACT, including the administration of different cycles of ACT and prescribed regimens, which might have been affected by physicians' preferences. More multi-institutional, prospective, randomized clinical trials should be performed to validate the survival benefits conferred by ACT in stage IB NSCLC patients.

\section{Conclusions}

The present study indicated that ACT is associated with improved survival in stage IB NSCLC patients irrespective of histology. Different ACT regimens were found to benefit patients with stage IB NSCLC. Prospective studies should be initiated to investigate the optimal ACT regimens in different histologic types in stage IB NSCLC patients.

\section{Acknowledgments}

Funding: This study was supported by funding from the Jiangsu Key Research and Development Plan (Social Development) Project (no. BE2020653), the Suzhou Key Discipline for Medicine (no. SZXK201803), the Suzhou Key Laboratory of Thoracic Oncology (no. SZS201907), the Municipal Program of People's Livelihood Science and Technology in Suzhou (SS2019061), Special Project of Diagnosis and Treatment Technology for Key Diseases in Suzhou (no. LCZX202004), and Discipline Construction Project of the Second Affiliated Hospital of Soochow University (no. XKTJ-XK202004).

\section{Footnote}

Reporting Checklist: The authors have completed the PRISMA reporting checklist. Available at https://dx.doi. org/10.21037/atm-21-4001

Conflicts of Interest: All authors have completed the ICMJE uniform disclosure form (available at https://dx.doi. org/10.21037/atm-21-4001). The authors have no conflicts of interest to declare.

Ethical Statement: The authors are accountable for all aspects of the work in ensuring that questions related to the accuracy or integrity of any part of the work are appropriately investigated and resolved.

Open Access Statement: This is an Open Access article distributed in accordance with the Creative Commons Attribution-NonCommercial-NoDerivs 4.0 International License (CC BY-NC-ND 4.0), which permits the noncommercial replication and distribution of the article with the strict proviso that no changes or edits are made and the original work is properly cited (including links to both the formal publication through the relevant DOI and the license). See: https://creativecommons.org/licenses/by-nc-nd/4.0/.

\section{References}

1. Siegel RL, Miller KD, Fuchs HE, et al. Cancer Statistics, 2021. CA Cancer J Clin 2021;71:7-33.

2. Arenberg D. Update on screening for lung cancer. Transl Lung Cancer Res 2019;8:S77-87.

3. National Lung Screening Trial Research Team; Aberle DR, Adams AM, et al. Reduced lung-cancer mortality with low-dose computed tomographic screening. $\mathrm{N}$ Engl J Med 2011;365:395-409.

4. Moore DA, Brownlee L, Rathbone VM. Pathology of Lung Cancer. 2020. Doi: 10.1016/B978-0-12-8012383.11700-3.

5. Detterbeck FC, Boffa DJ, Kim AW, et al. The Eighth Edition Lung Cancer Stage Classification. Chest 2017;151:193-203.

6. Varlotto JM, Recht A, Flickinger JC, et al. Factors associated with local and distant recurrence and survival in patients with resected nonsmall cell lung cancer. Cancer 2009;115:1059-69.

7. Hung JJ, Wu YC, Chou TY, et al. Adjuvant Chemotherapy Improves the Probability of Freedom From Recurrence in Patients With Resected Stage IB Lung Adenocarcinoma. Ann Thorac Surg 2016;101:1346-53.

8. Qian F, Yang W, Wang R, et al. Prognostic significance and adjuvant chemotherapy survival benefits of a solid or micropapillary pattern in patients with resected stage IB lung adenocarcinoma. J Thorac Cardiovasc Surg 2018;155:1227-1235.e2.

9. Xu J, Wang S, Zhong H, et al. Adjuvant Chemotherapy Improves Survival in Surgically Resected Stage IB Squamous Lung Cancer. Ann Thorac Surg 2019;107:1683-9.

10. Strauss GM, Herndon JE 2nd, Maddaus MA, et al. Adjuvant paclitaxel plus carboplatin compared with observation in stage IB non-small-cell lung cancer: 
CALGB 9633 with the Cancer and Leukemia Group B, Radiation Therapy Oncology Group, and North Central Cancer Treatment Group Study Groups. J Clin Oncol 2008;26:5043-51.

11. Rami-Porta R, Bolejack V, Crowley J, et al. The IASLC Lung Cancer Staging Project: Proposals for the Revisions of the T Descriptors in the Forthcoming Eighth Edition of the TNM Classification for Lung Cancer. J Thorac Oncol 2015;10:990-1003.

12. Shamseer L, Moher D, Clarke M, et al. Preferred reporting items for systematic review and meta-analysis protocols (PRISMA-P) 2015: elaboration and explanation. BMJ 2015;350:g7647.

13. Chen D, Mao Y, Wen J, et al. Tumor Spread Through Air Spaces in Non-Small Cell Lung Cancer: A Systematic Review and Meta-Analysis. Ann Thorac Surg 2019;108:945-54.

14. Jiang T, Qiao M, Zhao C, et al. Pretreatment neutrophil-to-lymphocyte ratio is associated with outcome of advanced-stage cancer patients treated with immunotherapy: a meta-analysis. Cancer Immunol Immunother 2018;67:713-27.

15. Higgins JP, Thompson SG, Deeks JJ, et al. Measuring inconsistency in meta-analyses. BMJ 2003;327:557-60.

16. Duval S, Tweedie R. Trim and fill: A simple funnel-plotbased method of testing and adjusting for publication bias in meta-analysis. Biometrics 2000;56:455-63.

17. Wang Y, Zheng D, Chen T, et al. Survival Prediction and Adjuvant Chemotherapy Based on Tumor Marker for Stage IB Lung Adenocarcinoma. Ann Thorac Surg 2020;109:927-37.

18. Chen D, Wang X, Zhang F, et al. Could tumor spread through air spaces benefit from adjuvant chemotherapy in stage I lung adenocarcinoma? A multi-institutional study. Ther Adv Med Oncol 2020;12:1758835920978147.

19. Jang HJ, Cho S, Kim K, et al. Effect of Adjuvant Chemotherapy after Complete Resection for Pathologic Stage IB Lung Adenocarcinoma in High-Risk Patients as Defined by a New Recurrence Risk Scoring Model. Cancer Res Treat 2017;49:898-905.

20. Ito H, Nakayama H, Nagashima T, et al. The adjuvant chemotherapy can be omitted for lepidic predominant lung adenocarcinoma in stage IB of the 8th TNM staging system. Cancer Biol 2020. Doi: 10.21203/rs.2.21919/v1.

21. Cao S, Teng J, Xu J, et al. Value of adjuvant chemotherapy in patients with resected stage IB solid predominant and solid non-predominant lung adenocarcinoma. Thorac Cancer 2019;10:249-55.
22. Chen T, Luo J, Gu H, et al. Impact of Solid Minor Histologic Subtype in Postsurgical Prognosis of Stage I Lung Adenocarcinoma. Ann Thorac Surg 2018;105:302-8.

23. Wang J, Wu N, Lv C, et al. Should patients with stage IB non-small cell lung cancer receive adjuvant chemotherapy? A comparison of survival between the 8 th and 7 th editions of the AJCC TNM staging system for stage IB patients. J Cancer Res Clin Oncol 2019;145:463-9.

24. Morgensztern D, Du L, Waqar SN, et al. Adjuvant Chemotherapy for Patients with T2N0M0 NSCLC. J Thorac Oncol 2016;11:1729-35.

25. Butts CA, Ding K, Seymour L, et al. Randomized phase III trial of vinorelbine plus cisplatin compared with observation in completely resected stage IB and II nonsmall-cell lung cancer: updated survival analysis of JBR-10. J Clin Oncol 2010;28:29-34.

26. Kawase A, Yoshida J, Ishii G, et al. Differences between squamous cell carcinoma and adenocarcinoma of the lung: are adenocarcinoma and squamous cell carcinoma prognostically equal? Jpn J Clin Oncol 2012;42:189-95.

27. Fukui T, Taniguchi T, Kawaguchi K, et al. Comparisons of the clinicopathological features and survival outcomes between lung cancer patients with adenocarcinoma and squamous cell carcinoma. Gen Thorac Cardiovasc Surg 2015;63:507-13.

28. Maeda H, Matsumura A, Kawabata T, et al. Adenosquamous carcinoma of the lung: surgical results as compared with squamous cell and adenocarcinoma cases. Eur J Cardiothorac Surg 2012;41:357-61.

29. Poleri C, Morero JL, Nieva B, et al. Risk of recurrence in patients with surgically resected stage I non-small cell lung carcinoma: histopathologic and immunohistochemical analysis. Chest 2003;123:1858-67.

30. Buhl IK, Santoni-Rugiu E, Ravn J, et al. Molecular prediction of adjuvant cisplatin efficacy in Non-Small Cell Lung Cancer (NSCLC)-validation in two independent cohorts. PLoS One 2018;13:e0194609.

31. Lin MW, Wu CT, Shih JY, et al. Clinicopathologic characteristics and prognostic significance of EGFR and p5 3 mutations in surgically resected lung adenocarcinomas $\leq 2 \mathrm{~cm}$ in maximal dimension. J Surg Oncol 2014;110:99-106.

32. Ma X, Rousseau V, Sun H, et al. Significance of TP53 mutations as predictive markers of adjuvant cisplatin-based chemotherapy in completely resected non-small-cell lung cancer. Mol Oncol 2014;8:555-64.

33. Kuang PP, Li N, Liu Z, et al. Circulating Tumor DNA Analyses as a Potential Marker of Recurrence 
and Effectiveness of Adjuvant Chemotherapy for Resected Non-Small-Cell Lung Cancer. Front Oncol 2021;10:595650.

34. Ulrich B, Pradines A, Mazières J, et al. Detection of Tumor Recurrence via Circulating Tumor DNA Profiling in Patients with Localized Lung Cancer: Clinical Considerations and Challenges. Cancers (Basel) 2021;13:3759.

35. Reck M, Rodríguez-Abreu D, Robinson AG, et al. KEYNOTE-024 Investigators. Pembrolizumab versus Chemotherapy for PD-L1-Positive Non-Small-Cell Lung

Cite this article as: Wang X, Chen D, Wen J, Mao Y, Zhu X, Fan M, Chen Y. Benefit of adjuvant chemotherapy for patients with stage IB non-small cell lung cancer: a systematic review and meta-analysis. Ann Transl Med 2021;9(18):1430. doi: 10.21037/atm-21-4001
Cancer. N Engl J Med 2016;375:1823-33.

36. Garassino MC, Gadgeel S, Esteban E, et al. Patientreported outcomes following pembrolizumab or placebo plus pemetrexed and platinum in patients with previously untreated, metastatic, non-squamous non-small-cell lung cancer (KEYNOTE-189): a multicentre, double-blind, randomised, placebo-controlled, phase 3 trial. Lancet Oncol. 2020;21:387-97.

(English Language Editor: J. Gray) 


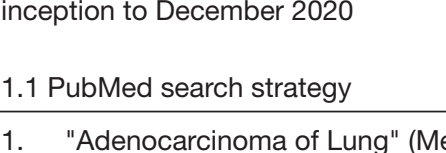

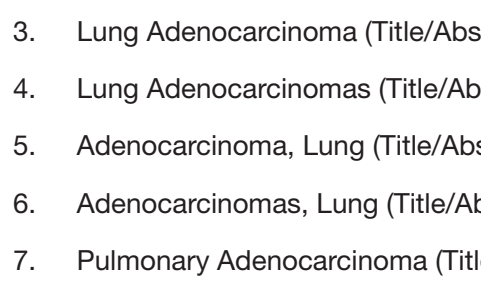

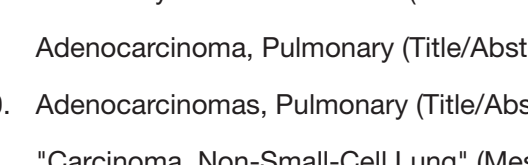

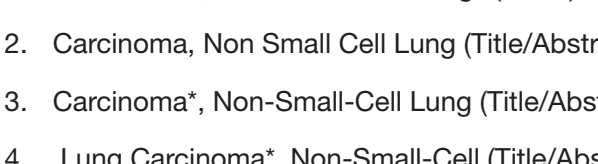

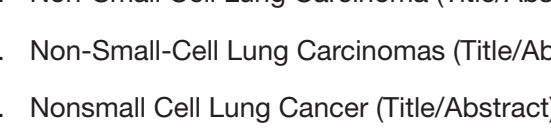

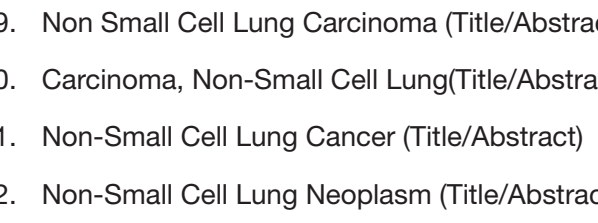

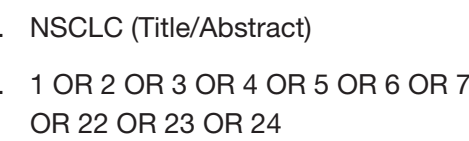

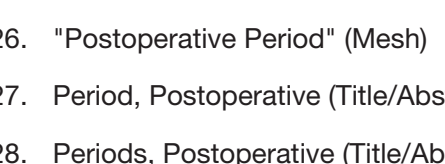

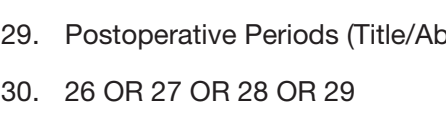

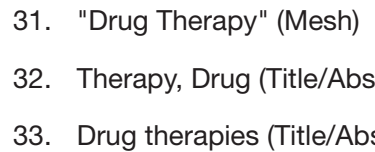

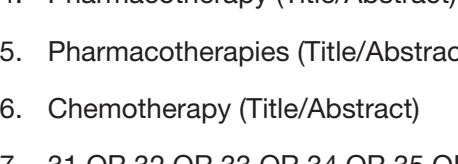

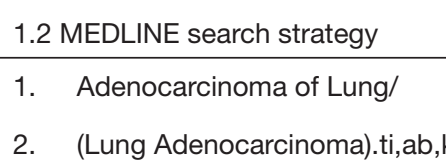

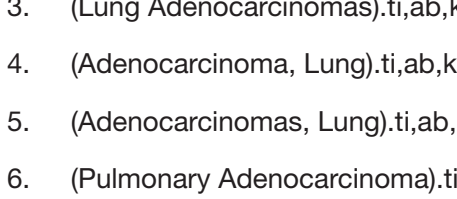

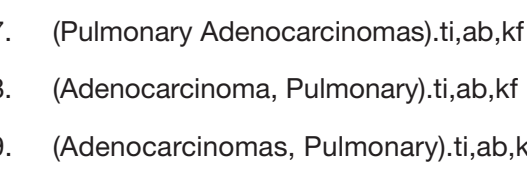

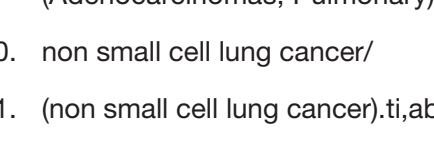

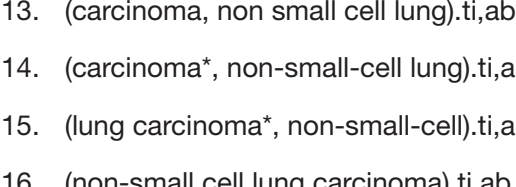

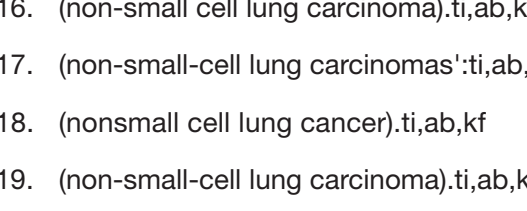

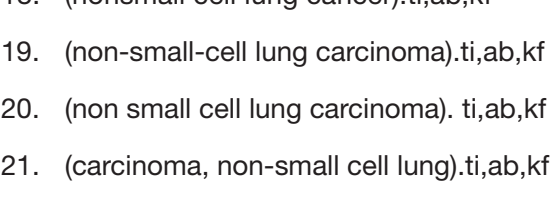

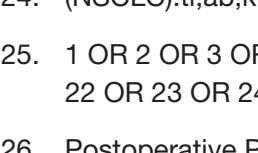

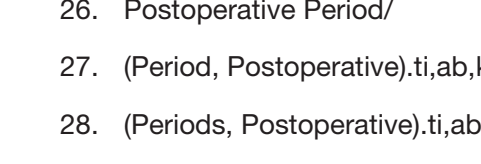

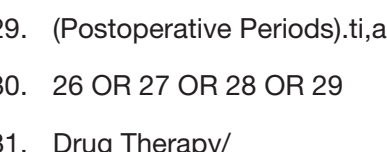

(Thereap, Drog)

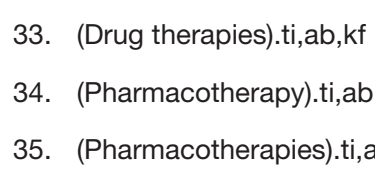

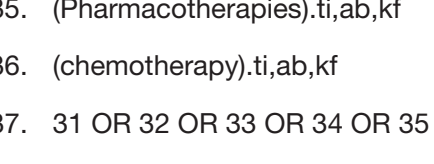

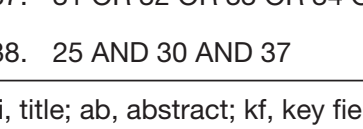

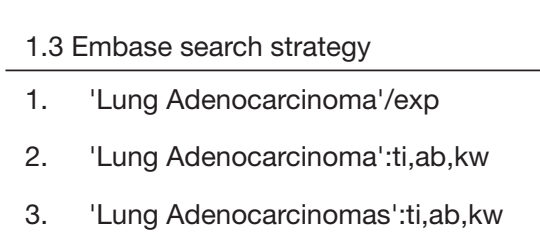

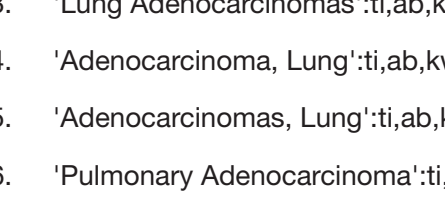

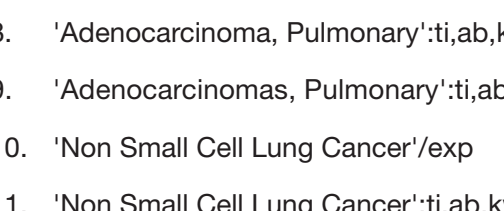

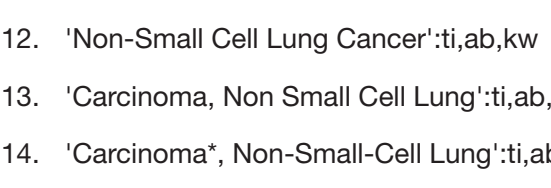

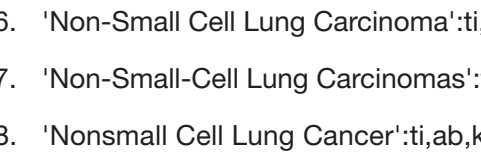

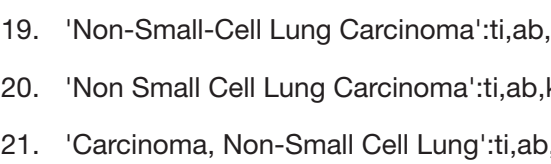

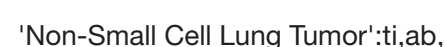

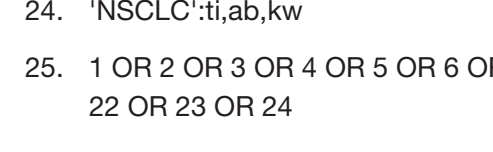

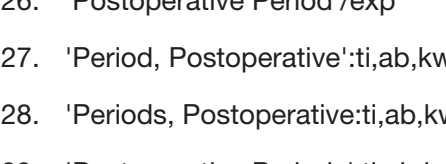

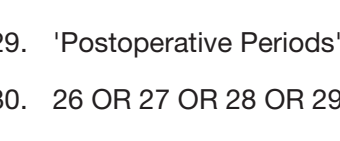

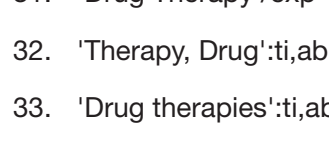

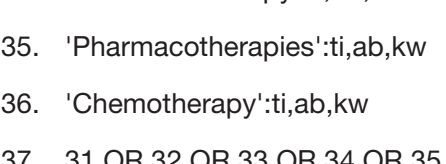

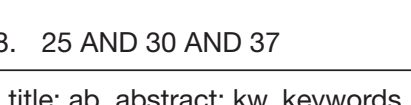

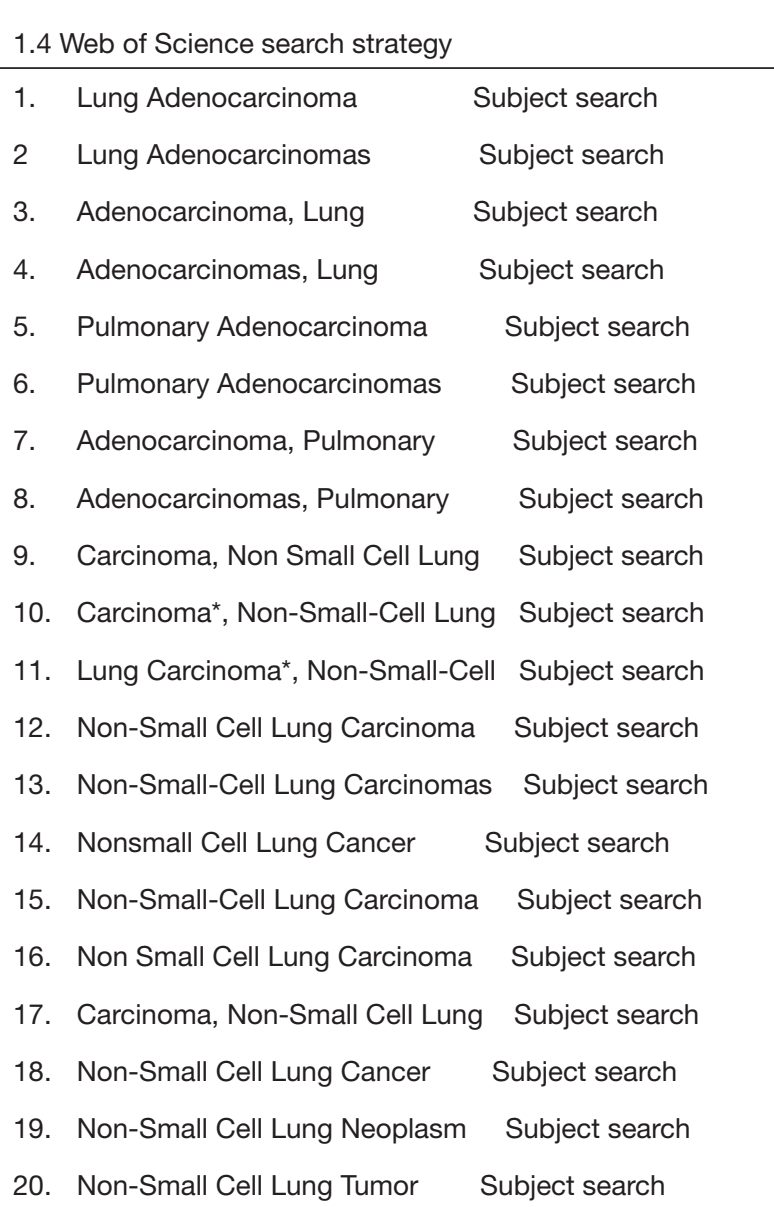

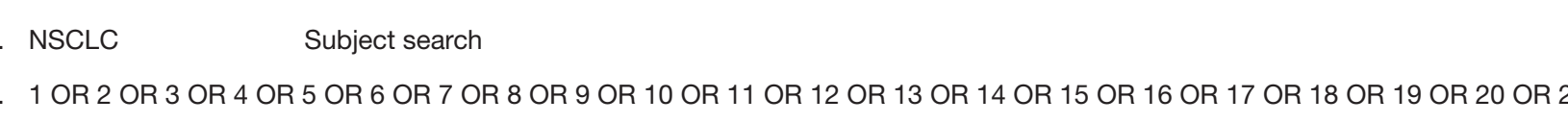

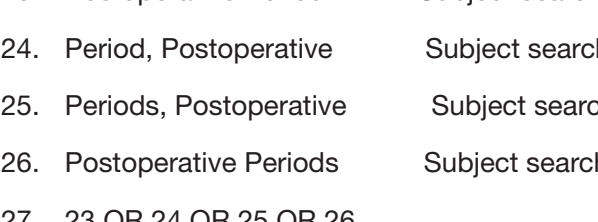

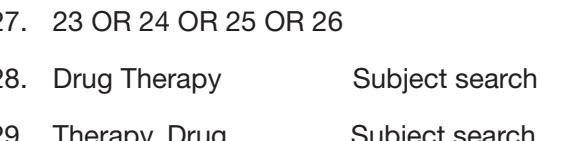

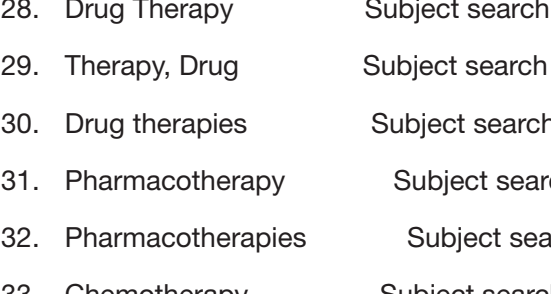

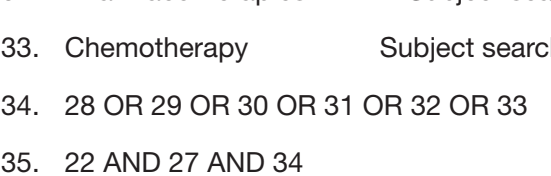

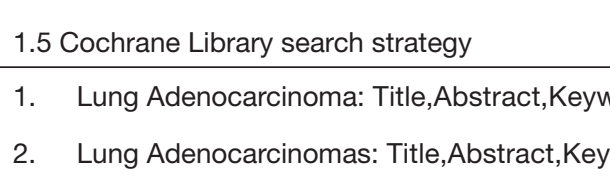

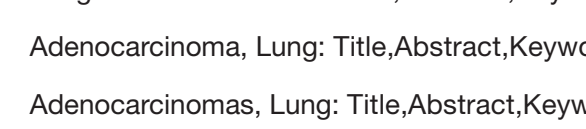

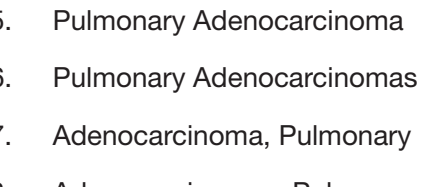

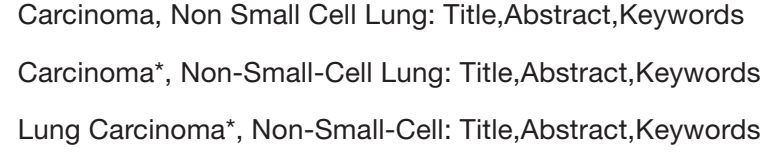

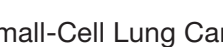

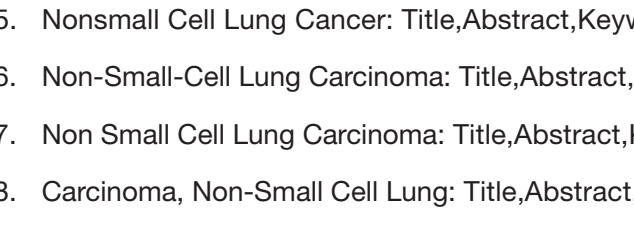

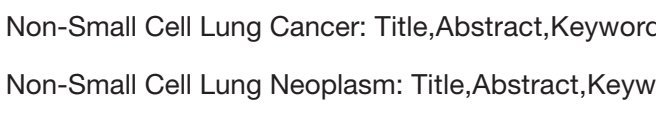

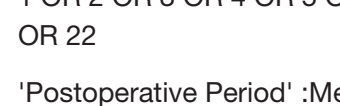

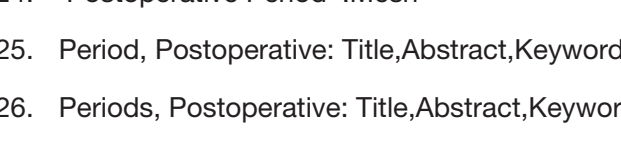

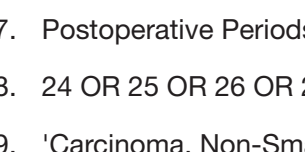

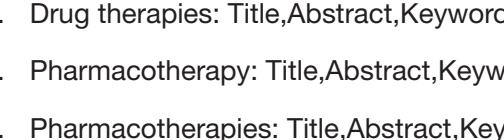


Table S2 Main characteristics of the included studies ( $\mathrm{n}=12)$

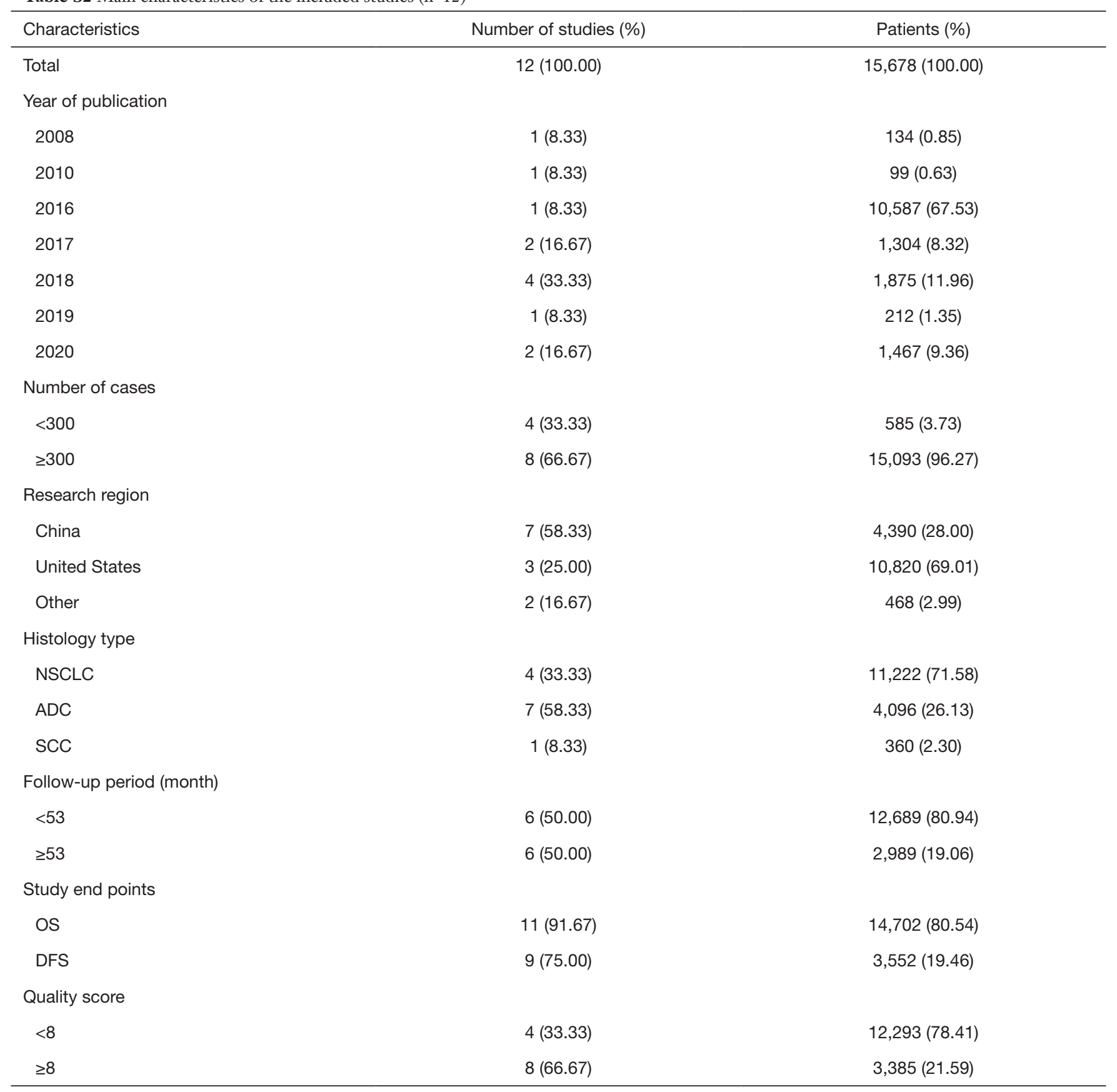

NSCLC, non-small cell lung cancer; ADC, adenocarcinoma; SCC, squamous cell carcinoma; OS, overall survival; DFS, disease-free survival. 
Table S3 Quality assessment of the included studies ( $\mathrm{n}=12)$

\begin{tabular}{|c|c|c|c|c|c|c|c|c|c|}
\hline No. & Author & $\begin{array}{c}\text { Representativeness } \\
\text { of population }\end{array}$ & Nonexposed cohort & $\begin{array}{l}\text { Ascertainment of } \\
\text { exposure }\end{array}$ & $\begin{array}{l}\text { Outcome not } \\
\text { present at start of } \\
\text { study }\end{array}$ & $\begin{array}{l}\text { Appropriate } \\
\text { confounding } \\
\text { measurement and } \\
\text { account }\end{array}$ & $\begin{array}{c}\text { Sufficient } \\
\text { measurement of } \\
\text { outcomes }\end{array}$ & $\begin{array}{l}\text { Completeness of } \\
\text { follow-up }\end{array}$ & Quality score \\
\hline 1 & Morgensztern [2016] & 0 & 1 & 1 & 1 & 2 & 1 & 1 & 7 \\
\hline 2 & Xu [2018] & 0 & 1 & 1 & 1 & 2 & 1 & 2 & 8 \\
\hline 3 & Strauss [2008] & 0 & 1 & 1 & 1 & 2 & 1 & 2 & 8 \\
\hline 4 & Qian [2017] & 0 & 1 & 1 & 1 & 2 & 1 & 1 & 7 \\
\hline 5 & Butts [2010] & 0 & 1 & 1 & 1 & 2 & 1 & 2 & 8 \\
\hline 6 & Wang [2018] & 0 & 1 & 1 & 1 & 2 & 1 & 1 & 7 \\
\hline 7 & Wang [2019] & 0 & 1 & 1 & 1 & 2 & 1 & 2 & 8 \\
\hline 8 & Chen [2020] & 0 & 1 & 1 & 1 & 2 & 1 & 2 & 8 \\
\hline 9 & Jang [2017] & 0 & 1 & 1 & 1 & 2 & 1 & 1 & 7 \\
\hline 10 & Ito [2020] & 0 & 1 & 1 & 1 & 2 & 1 & 2 & 8 \\
\hline 11 & Cao [2018] & 0 & 1 & 1 & 1 & 2 & 1 & 2 & 8 \\
\hline 12 & Chen [2018] & 0 & 1 & 1 & 1 & 2 & 1 & 2 & 8 \\
\hline
\end{tabular}

\begin{tabular}{lcc}
\multicolumn{2}{l}{ Table S4 The publication bias assessment with different tests for OS and DFS } \\
\hline Publication bias & Begg's P value & Egger's P value \\
\hline OS & 0.436 & 0.379 \\
DFS & 1.000 & 0.481 \\
\hline
\end{tabular}




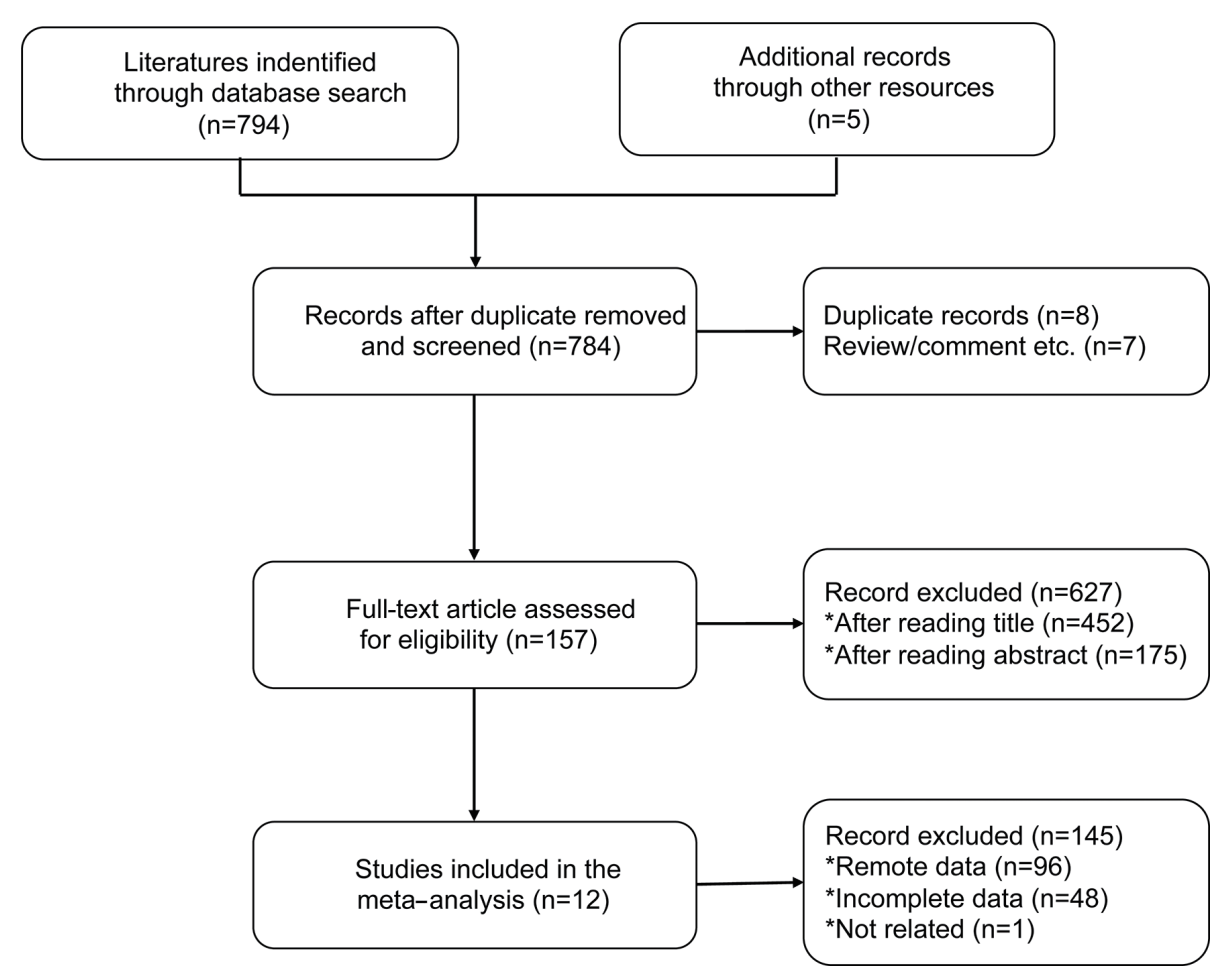

Figure S1 Literature Search of Eligible Studies.

subgroup and study

$\mathrm{HR}(95 \% \mathrm{Cl})$

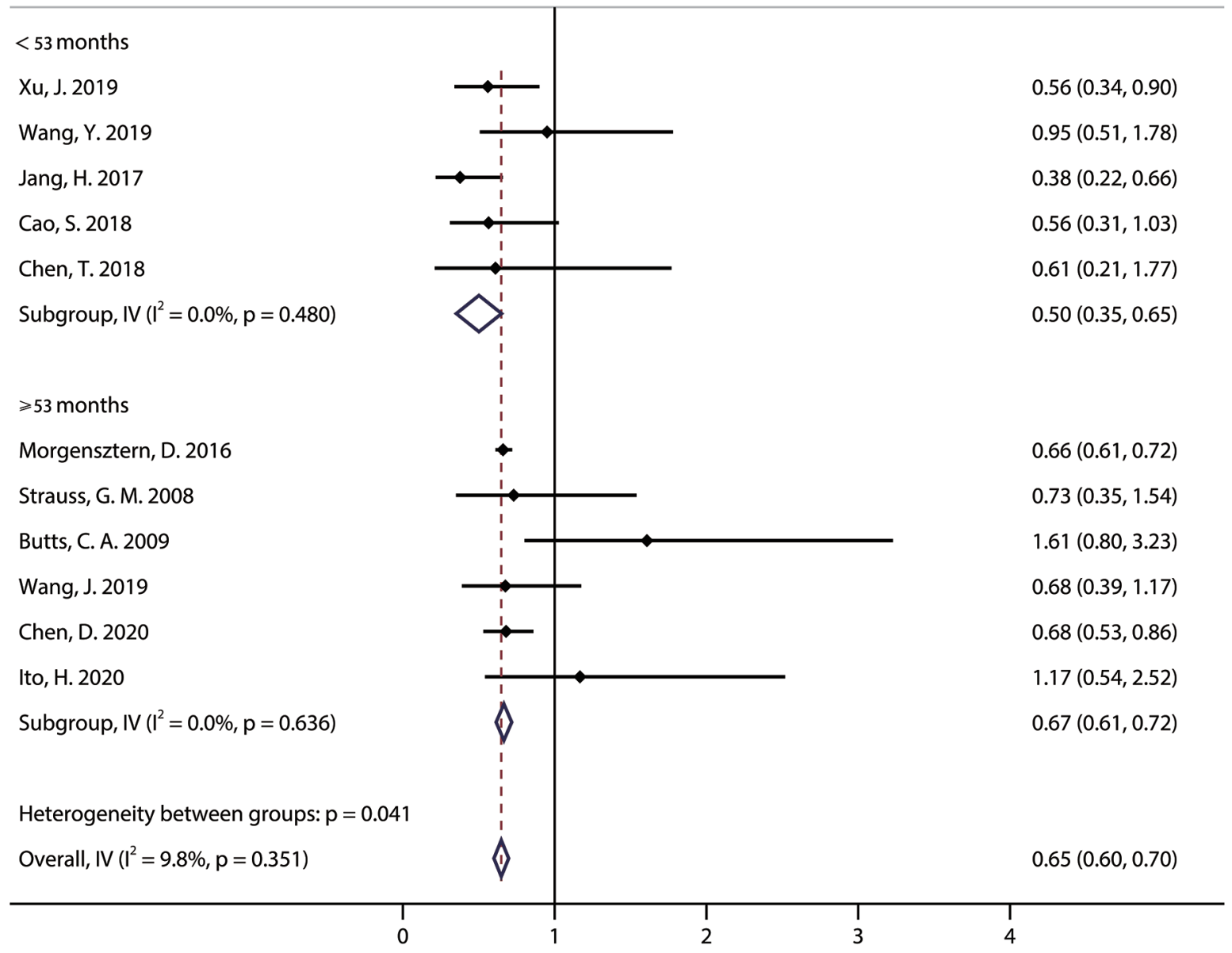

Figure S2 Subgroup Analyses of the Associations between Follow-Up Periods and Overall Survival (OS). 